\title{
INTEGRATION OF IT SYSTEMS SUPPORTING PRODUCTION MANAGEMENT
}

\author{
Elżbieta MILEWSKA \\ Silesian University of Technology, Faculty of Organization and Management; Elzbieta.Milewska@polsl.pl, \\ ORCID: 0000-0001-8053-4333
}

Purpose: The main purpose of this paper was to present the possibilities of integration of IT systems supporting the management of a production company on the strategic, tactical and operational level.

Design/methodology/approach: The paper discusses the definition of the concept of systems integration and reviews the existing methods of integration at the level of data and processes. Activities that contribute to the ordering of data sets and increasing the effectiveness of information use are also presented.

Findings: This paper presents a case of vertical integration of systems. The strategic level of management was represented by the ERP class system, the tactical level was supported by the MES system, while on the executive (operational) level the author used the SCADA system. Functional connections of ERP-MES-SCADA systems were discussed and conditions and requirements related to their integration were presented. Moreover, problems related to data exchange were described.

Research limitations/implications: The author of the paper pointed out that the requirements related to the frequency and scope of data synchronization are an extremely important element of the process of designing communication systems integrating industrial automation devices with database IT systems. It is also necessary to grant access rights to the integration mechanisms in order to modify or audit them. Moreover, the effectiveness of the solution is affected by the changes introduced in the engines of the integrated databases, as they often cause the need to modify the integration mechanism, while the use of dedicated solutions is associated with the risk of high maintenance costs.

Practical implications: The paper indicates that the integration of systems is particularly important for manufacturing companies. It provides a platform for cooperation between internal units, enabling ongoing monitoring of manufacturing processes, and predisposes the organization to engage in integrated supply chains, resulting in an increase in the scope of cooperation and the scope of the company's activity.

Originality/value: Undoubtedly, an original element of the paper is the presentation of data exchange schemes between ERP-MES and MES-SCADA systems.

Keywords: digital transformation, Industry 4.0, smart factories.

Category of the paper: Research paper, Case study. 


\section{Introduction}

Striving for effective data exchange between internal units of the organization, as well as efficient communication with external business entities, forces the company to take actions aimed at integration of IT systems. It enables to increase the effectiveness of basic business processes by making auxiliary processes more flexible, as well as eliminating errors and delays resulting from recording events, replacing the human factor by using the Internet of Things (IIoT - Industrial Internet of Things). The integration of information systems is particularly important for manufacturing companies. It constitutes a platform for cooperation of internal units, enabling current tracking of the course of manufacturing processes and predisposes the organization to be included in integrated supply chains, owing to which the scope of cooperation and the scope of economic activity of the organization increases. It is not an easy task due to the diversity of applied standards, protocols and communication interfaces, as well as inconsistency of data describing the same business events in different databases. When choosing the method of integration, one should take into account: the aim of the action, its scope and subject matter, as well as the dimension of the organizational structure, the economic, technical, technological and social sphere of the enterprise. It should also be mentioned, that the integration of systems is part of the changes brought about by the fourth industrial revolution, the so-called Industry 4.0 (Gilchrist, 2016).

\section{Case study on the functional interconnection of IT systems}

Currently, the foundation of production process management and material flow control in the company and the basic condition for the integration of business activities is the implementation of IT systems supporting the acquisition, processing and transmission of information (Milewska 2016, 2017). They are particularly useful for the sector of large manufacturing companies, at the strategic, tactical and operational level of organization management. This paper will present a case of vertical integration of selected classes of management systems (Figure 1), which support each of the mentioned levels. The strategic level will be represented by the ERP class system, the tactical level will be supported by the MES system, while the SCADA system will be used at the executive (operational) level. The functional connection of the ERP-MES-SCADA systems will be discussed below and the conditions and requirements related to their integration will be presented. 


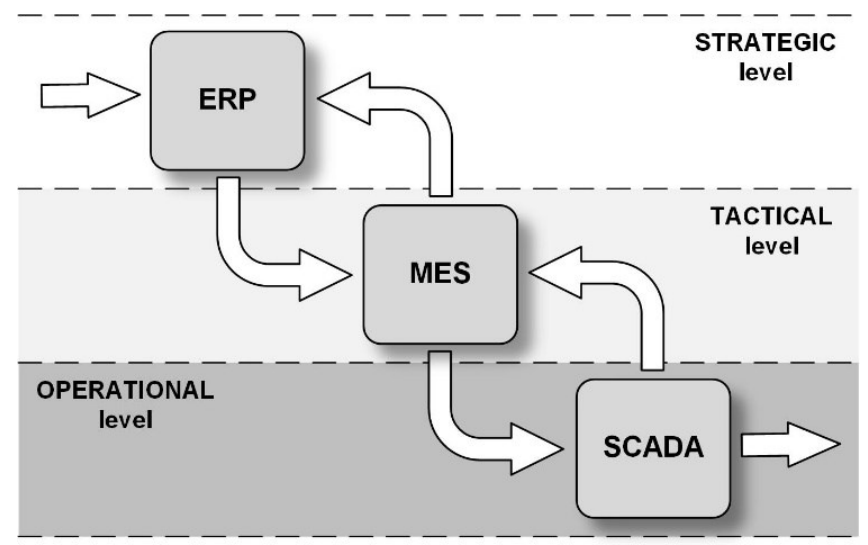

Figure 1. Vertical integration of ERP-MES-SCADA systems. Source: own elaboration.

The ERP class system (Enterprise Resource Planning) is currently the most frequently used integrated IT system in the sector of large Polish manufacturing companies. It is mainly used to manage the organization at the strategic level. It enables standardization of business processes, consolidation of financial information influencing managerial decisions, customer order handling taking into account the variability of demand for manufactured goods (Alsene, 1999, pp. 26-35) (Figure 2) and material stock levels, as well as ensures security and confidentiality of information. In the vast majority of cases, the standard functionality of ERP and MRP II (Manufacturing Resource Planning) systems allows recording events only through the participation of the human factor.

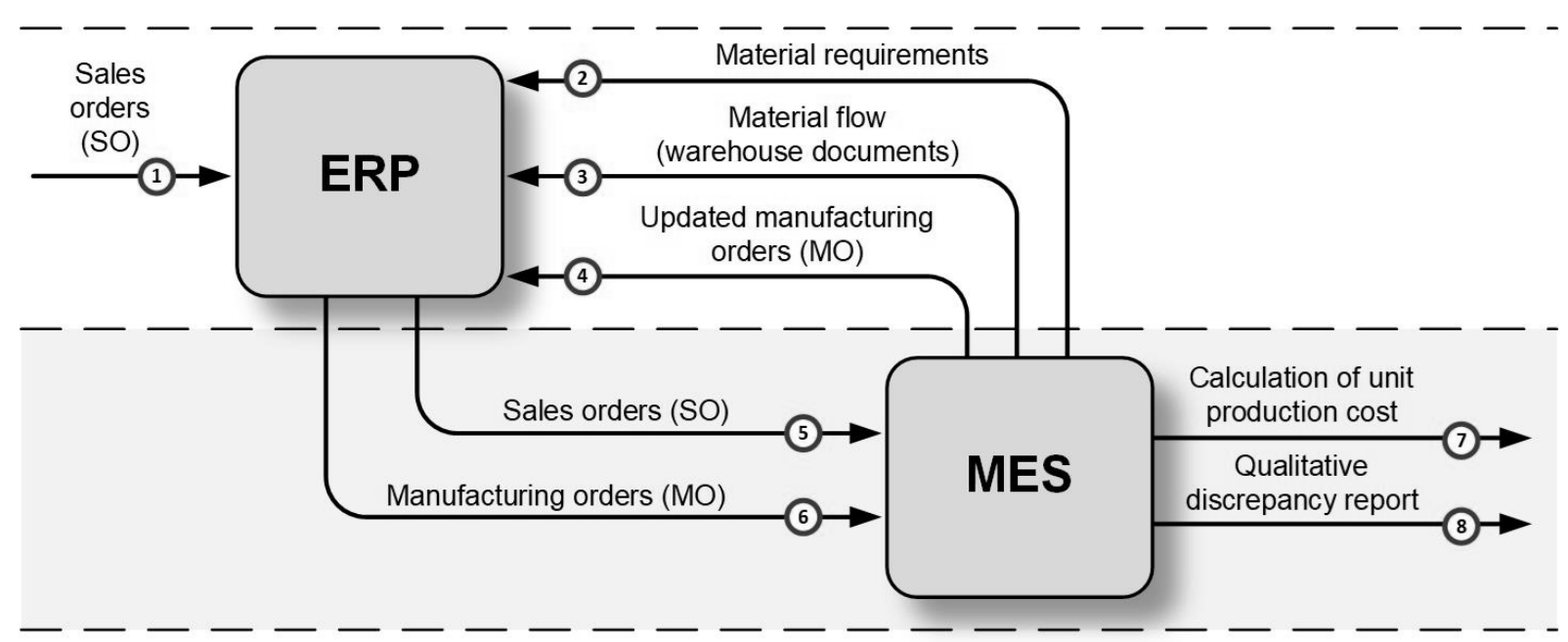

Figure 2. Scope of integration of ERP and MES class systems. Source: own elaboration.

At the tactical level, MES class systems (Manufacturing Execution Systems) are used, among others (Figure 2). They provide information on demand (Batini, Lenzerini, Navathe, 1986, pp. 323-364) and material consumption (Giachetti, 2004, pp. 1147-1166) (Figure 2). They are responsible for planning the manufacturing activity, which includes the whole organizational undertakings related to the allocation of production resources, i.e. assignment of an employee to the workstation in order to carry out the technological operation of the order 
(Henderson, Venkatraman, 1999, pp. 472-484) (Figure 2) using the indicated material. The allocation should take into account both the temporary availability of human resources, machinery and raw materials necessary for the execution of the tasks entrusted, as well as the adaptation of resources to the execution of the task and the various constraints regarding the workflow. Their effect should be to meet the quality standards of manufactured products. An important issue of cooperation between both ERP-MES systems is the integration of system data and bidirectional data transfer. The integration concerns both basic data, mapping the company's structures and processes, and transactional data resulting from the recording of economic events. Requesting and taking adaptive actions at the strategic level can only be achieved through feedback. The updated information covering the progress of works carried out within the production order (Godinez, Hechler, Koening, Lockwood, Oberhofer, Schroeck, 2010) (Figure 2) stimulates the time horizon of satisfying the needs (Greefhorst, Proper, 2011) (Figure 2) and by shortening the recipient's waiting time for the release of the finished product, it influences the level of customer service.

As an option, the functionality described above can be implemented by the ERP system module. Due to the parameterization and criteria of prioritization of manufacturing activities and planning of logistic processes, the alternative solutions are also APS class systems (Advanced Planning Scheduling). Their advanced algorithms enable autonomous creation of production flow scenarios, taking into account the complex nature of technological processes.

The effect of IT systems activities at the tactical level is the calculation of unit production cost (Kosanke, Vernadat, Zelm, 1999, pp. 83-97) and as-built quantitative statements, based on which actions are taken to eliminate the occurrence of quality discrepancies in the manufactured products (Lim, Juster, de Pennington, 1997, pp. 339-359) (Figure 2 and Figure 3).

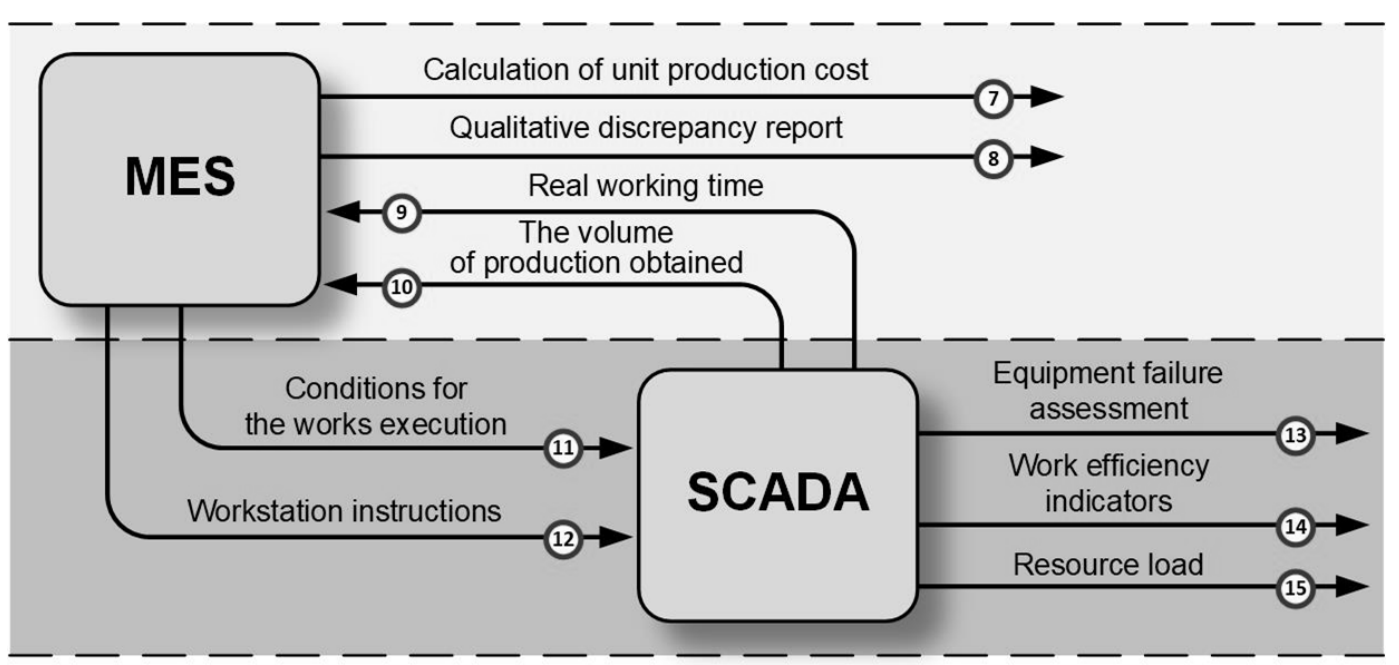

Figure 3. Scope of MES and SCADA class system integration. Source: own elaboration. 
The solution supporting the acquisition of information directly from the production line is the implementation of a SCADA class system (Supervisory Control and Data Acquisition) (Figure 3). It is located between the control, measuring and execution devices (such as I/O modules, PLCs, sensors, counters and test systems) and the machine operator. The course of manufacturing activities is undertaken on the basis of information provided to the executive (operational) level in the form of parameters describing the conditions for the execution of the works (Milewska, 2016, pp. 759-767) and in the form of workstation instructions (Milewska, 2017, pp. 60-67) (Figure 3). The latter reflect the allocation of resources made in the MES system. Through the automatic identification and industrial automation devices, data describing the actual course of processes (Luftman, 2003, pp. 7-20; Mejabi, Singh, 1997, pp. 212-220) (Figure 3) are obtained.

SCADA systems enable visualization of data in the perspective of currently conducted activities, but also presentation of archived statements. On their basis, the failure rate of technical equipment can be evaluated (Nugent, Hamblin, 1996, pp. 16-28), the value of work efficiency indicators can be determined (Petrie, 1992) and the variability of resource load can be demonstrated (Reich, Benbasat, 2000, pp. 81-113) (Figure 3). In addition, SCADA systems enable current supervision over the operation of machines, allowing the operator to react interactively to disturbances in the course of technological processes and elimination of these disturbances by changing the settings or the way of controlling the device and switching to manual mode or the operation of the resource in emergency mode.

The analysis of the functionality of ERP, MES and SCADA class systems allows to determine the mutual overlapping of application areas of the mentioned systems. Some modules of MRPII/ERP class systems may contain some of the functionality of a MES class system, while a MES class system may perform some basic tasks of an MRP II/ERP class system. A similar situation occurs with a pair of MES and SCADA systems. Quite rarely, but nevertheless, one can notice a permeation of ERP and SCADA system functionalities. An important issue of interoperability of the mentioned systems is system data integration and bidirectional data transfer. It should be noted that both the recording of working time and the recording of warehouse documents can be carried out using the systems of all the classes listed. An important element differentiating the applied solution is the accuracy and timeliness of data, which is the basis for further analysis. It is obvious that unreliability and labor intensity related to manual recording of events performed by the employee are the main factor limiting the efficiency of process organization. Incorrect input of data or excessive time burden for an employee, causing significant delays in recording events, distorts the picture of work progress and prevents analysis of the current situation. 


\section{Preparation of systems cooperation}

The issue of IT systems integration covers many aspects. Some of the proposed approaches address technical data exchange issues (Alsene, 1999; Batini et al. 1986; Truman, 1998), while others put organizational elements in the foreground (Lim et al., 1997; Nugent et al., 1996; Petrie, 1992, Vernadat, 1996). As far as information is concerned, integration means synergy oriented towards supporting business decision making. In addition to defining the concept of integration, many researchers are attempting to identify the components. In literature (Giachetti, 2004; Kosanke et al., 1999; Mejabi et al., 1997), the following forms of integration are generally distinguished:

- business integration,

- application integration,

- system integration.

These definitions show that the issue of integration is a complex concept and can be considered as an objective or subjective undertaking. However, the author of this paper adopts a definition indicating that integration is a set of activities aimed at improving processes taking place in an organization by defining and modifying links between internal units of the organization that participate in the implementation of the entrusted purpose.

Architectures and reference models are tools facilitating the integration of IT systems in terms of business processes. The term "reference models" is understood as models developed on the basis of the experience gained from conducting business activity of a company and implemented IT systems. They contain general guidelines dedicated to a specific industry or application area and form the basis for the development of an operating scenario (Greefhorst et al., 2011) and the criteria for evaluating implementation (Godinez et al., 2010; Luftman, 2003; Salmans, 2010). The word "reference", derived from the Latin word "referre", means recommendation in this context. Architectures and reference models enable the integration of the social sphere and the dimension of the organizational structure into the technical and technological sphere (Henderson et al., 1999; Reich, 2000).

Territorial dispersion of company's organizational units, heterogeneity of owned IT systems and inconsistency of data collected in them create difficulties in conducting business activity. Internal integration is one of the most significant tasks currently undertaken by organizations. Conducting the integration process means organizing data, as well as concurrent control of the information flow. Many publications, therefore, distinguish two basic components of integration: data and processes.

Interfaces are the basic element of the system integration model. Through them, information is transmitted from one system and received by another IT system. It is also referred to as modeling of message exchange, which should define the scope of data and the way and time of transaction execution. One of the open communication standards used in industrial automation 
and IT systems for managing manufacturing operations, is OPC (OLE for Process Control). It is designed to combine applications based on general purpose operating systems with hardware and application software for industrial automation, supervising and controlling the technological process. It is based on Microsoft OLE (Object Linking and Embedding), COM (Component Object Model) and DCOM (Distributed Component Object Model) standards, OPC technology makes monitoring software independent of various solutions used by process equipment manufacturers. Such devices include: sensors from different manufacturers, actuators, PLC (Programmable Logic Controller), RTU (Remote Terminal Unit), DCS (Distributed Control System), HMI (Human Machine Interface), trend handling systems, alarm systems and many others, which are used in various industries. Through OPC, access methods become independent of the type and source of data.

The task of integration at the data level comes down to the problem of harmonizing the way of understanding and presenting coherent content, standardizing the way of data processing and unifying the semantics of recording communication objects. The easiest way to exchange data between applications is to use text files. The integration performed by the files carries a low risk of violating the stability of the application, but the periodicity of data transfer always generates disproportionately long delays in recording data in the second system.

Another way of data exchange is to use dedicated database integration mechanisms. They are based on the consistency of dictionaries and the sharing of space for storing the messages exchanged. This way of operation requires precise planning of operations, taking into account transactions carried out by each party. The integration can take place through direct access of one system to the database of the other or through the use of a separate database space which mediates the exchange. It shall only be set up for the temporary storage of messages exchanged by the systems. Solutions based on shared database space allow bi-directional data exchange, which can be implemented without interfering with applications. However, attention should be paid to the limitations related to the definition of access rights to the integration mechanisms, in order to modify or audit them, and to the equivalence of the rights that are separately granted to users in each application. In addition, changes made to the integrated database engines have a significant impact on the effectiveness of the solution. Often, each time the developed version of the application is updated, the integration mechanism needs to be modernized and the documentation describing the interface needs to be supplemented. An unquestionable advantage of data exchange taking place using database communication is the time of data synchronization. This is because the exchange can take place with a frequency that allows to maintain the continuity of production processes without noticeable delays in data registration.

Integration of systems requires the creation and development of procedures to ensure communication. This can be done synchronously or asynchronously, i.e. in one direction. The use of international communication standards allows not only to obtain homogeneous data, but also to systematize the structure of connections with the process layer. These connections 
can be used with many different IT systems, increasing the efficiency of data transfer in a company.

\section{Areas of data exchange}

The basic scope of cooperation between the MES class system and the ERP class system covers the warehouse area. As part of data exchange, information on material availability is collected from the ERP system and information on material requirements is transferred to the ERP system. In addition, the exchange must include the data of material records, contractors, units of measurement, exchange rates etc. The exchange should be done automatically and activated cyclically. It normally includes newly entered data and data modified since the last synchronization with the MES system.

Figure 4 below shows an example diagram of information flow between the ERP system and the MES system. It distinguishes the functional areas of both systems and the objects involved in data exchange. The illustrated business process starts with a sales order (SO) submitted by the customer (Alsene, 1999, pp. 26-35) (Figure 4), which is entered into the ERP system by a sales department employee. On the basis of sales orders (SO documents) manufacturing orders (MO) are created, which document the course of the production process. Manufacturing orders in the MES system can be automatically generated on the basis of ERP system documents [A], created in response to the failure to meet the demand of other orders [B] or, regardless of the above, entered directly by the MES system user [C] (Figure 4). In the first case described above, the creation activity is performed by using the API.

An important condition for automating the process of task scheduling is the consistency of data describing both the acquired employee qualifications and the adaptation of the owned machine resources to perform particular tasks, as well as the description of the required skills, which are included in the product production technology.

Starting an order causes a demand for direct production materials. A collective demand analysis is periodically performed in the MES system. It determines the possibilities of fulfilling the company's obligations. It is based on the balance of stocks and issued purchase orders (PO).

Insufficient stocks of direct production materials stop the start of production works. They are supplemented by launching production of a semi-finished product or by the purchase of materials [a] (Figure 4). Achieving the minimum stock levels may automatically initiate the launch of procedures to supplement the quantity of material. Purchase orders (PO) created in the MES system are transferred to the ERP class system. The registration of goods received notes (GR) is carried out by the ERP system user, who is usually represented by an employee of the Procurement Department. 


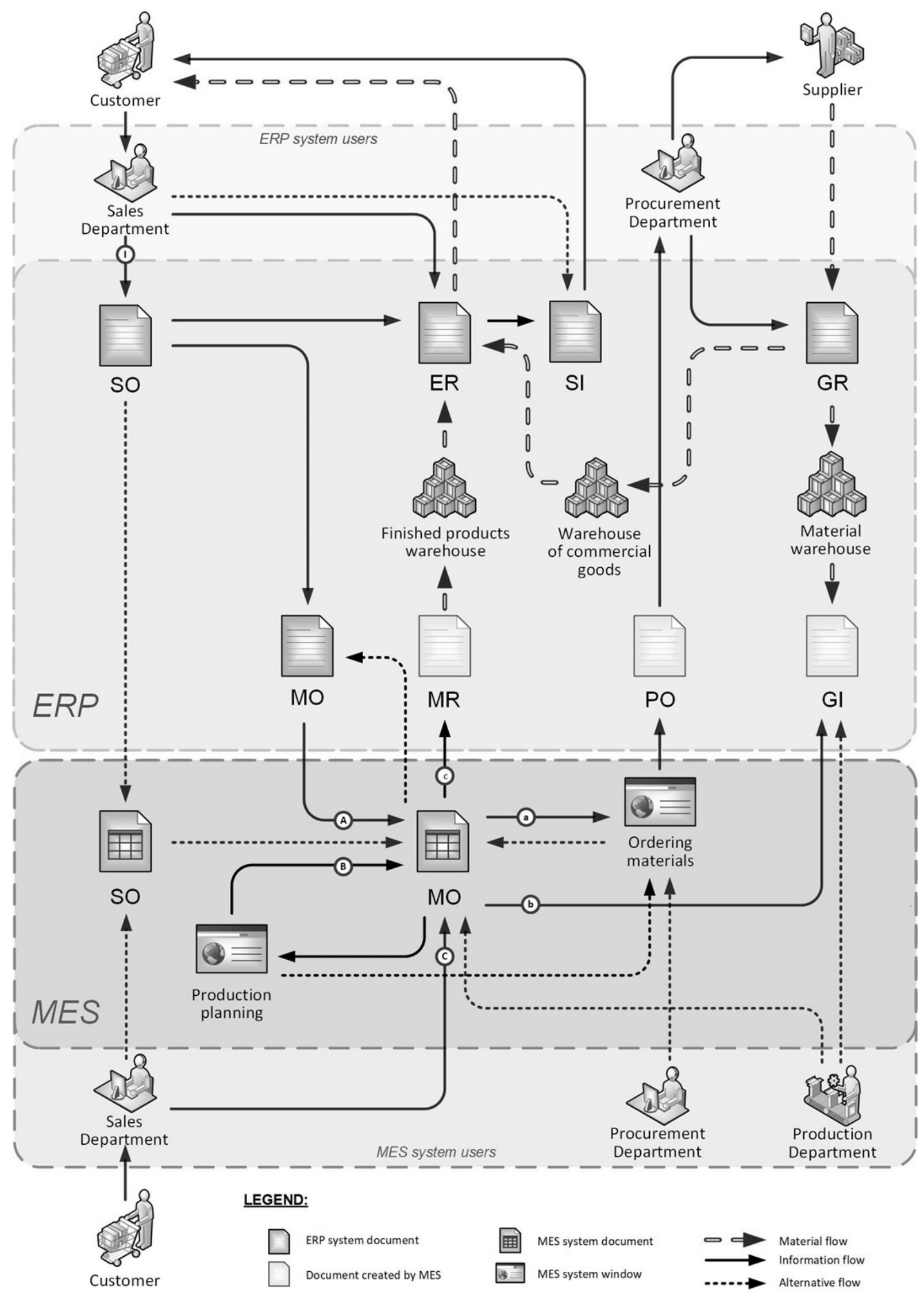

Figure 4. Data exchange scheme of the ERP class system with the MES system. Source: own elaboration. 
Only the confirmation of availability of all materials, declared in the form of a need for an order, allows the employee to issue a sheet entitling them to collect materials from the warehouse and to give an instruction to perform a technological operation. The material release is documented by the creation of a goods issue document (GI) [b] (Figure 4) in MES and transferring it to the ERP class system.

The completion of a production order automatically triggers the creation of a materials returns note (MR) in the MES and its transfer to the ERP system [c] (Figure 4).

Since the handling of stock is carried out in the ERP system, the external release of the product (ER) (Figure 4) takes place as a consequence of registration of the document by an employee of the sales department who is an ERP system user. On its basis, a sales invoice (SI) is generated, which, in the next step, is forwarded to the customer. The activities described are shown in the diagram above (Figure 4).

The basic benefits of automating these processes include the integrity of the material and information flow, as well as the timeliness of data describing:

- the degree of execution of orders,

- control of the implementation of production plans,

- reduction in stock levels.

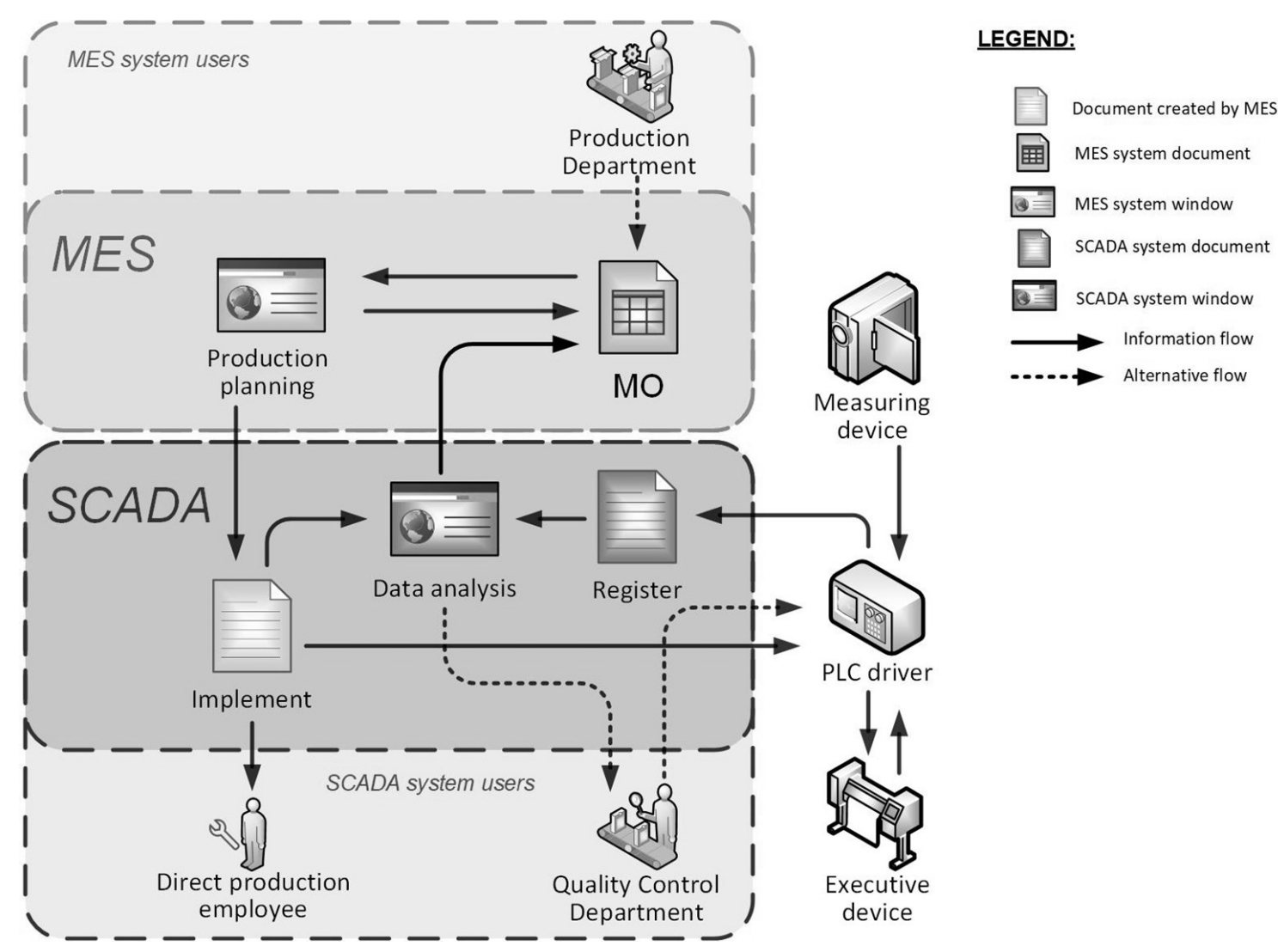

Figure 5. Data exchange scheme of the MES class system with the SCADA system. Source: own elaboration. 
Data exchange taking place among the control, measuring and executive devices, as well as the system and the user of the MES and SCADA systems is shown in Figure 5. The order to implement manufacturing activities is transferred from the MES system to the executive level. It represents the allocation of resources, i.e. the assignment of an employee to a workstation and a technological operation, as well as constitutes a performance plan. Whereas the data obtained from industrial automation devices describe the actual course of processes. Both values are compared in the SCADA system. As a result of data analysis, the evaluation of work and load of owned resources is performed. The identified disturbances are the basis for updating orders processed in the MES system. The described activities can also be supported by both RFID technology and the devices of the Industrial Internet of Things (IIoT).

Proper data interpretation and efficient inference taking place in the SCADA system can contribute to:

- identification of the causes of downtime and failures, as well as the impact on reducing machine failure,

- reporting process indicators, i.e. effectiveness and efficiency,

- identification of the product's genealogy and influence on its quality parameters.

\section{Summary}

The changes taking place in the modern environment force companies to modify their behavior. The solution which increases flexibility of operations and production efficiency is not only the implementation of IT systems, but also the integration of existing solutions. Production planning and control can be supported by the functionality of many systems. However, regardless of the classes of IT systems that a company decides to implement, full computerization of business processes allows to meet the demands of growing competitiveness and is one of the ways to develop a company in the era of globalization of the economy. On the other hand, automation of information flow in the production control system allows to increase the degree of utilization of production capacity and optimize the size of the company's intensive and extensive reserves.

However, in the automated flow of information, it is necessary to narrow down the scope of data processing to changes of a non-investment nature. The use of additional financial sources connected with increasing shift systems, technological modernization or expansion of the machine park should be implemented only through decisions of the management.

In the process of designing communication systems integrating industrial automation devices with database IT systems of the area of business management and production control, the requirements related to the frequency and scope of data synchronization are extremely important. It is also necessary to pay attention to the definition of access rights to integration 
mechanisms, in order to modify or audit them, and to the equivalence of rights that are separately granted to users in each application. In addition, the effectiveness of the solution is affected by the changes introduced in the integrated database engines. They often cause the need to modernize the integration mechanism and supplement the documentation describing the interface. In this context, it should be remembered that the use of dedicated integration solutions is associated with the risk of drastically increasing maintenance costs.

\section{Acknowledgements}

This article was created as part of statutory work BK-235/ROZ-1/2020 (13/010/BK_20/ 0042) conducted at the Institute of Economics and Informatics at the Faculty of Organisation and Management of the Silesian University of Technology.

\section{References}

1. Alsene, E. (1999). The computer integration of the enterprise. IEEE Transaction on Engineering Management, 46(1), 26-35, doi: 10.1109/17.740033.

2. Batini, C., Lenzerini, M., Navathe, S.B. (1986). A comparative analysis of methodologies for database schema integration. ACM Computing Surveys, 18(4), 323-364, doi: $10.1145 / 27633.27634$.

3. Giachetti, R.E. (2004). A framework to review the information integration of the enterprise. International Journal of Production Research, 42(6), 1147-1166, doi: 10.1080/ 00207540310001622430 .

4. Godinez, M., Hechler, E., Koening, K., Lockwood, S., Oberhofer, M., Schroeck, M. (2010). The art of enterprise information architecture. A systems-based approach for unlocking business insight. New Jersey: IBM Press Pearson.

5. Greefhorst, D., Proper, E. (2011). Architecture principles, The cornerstones of enterprise architecture. Berlin: Springer-Verlag.

6. Henderson, J.C., Venkatraman, N. (1999). Strategic alignment: Leveraging information technology for transforming organizations. IBM Systems Journal, 38(2-3), 472-484, doi: 10.1147/SJ.1999.5387096.

7. Kosanke, K., Vernadat, F., Zelm, M. (1999). CIMOSA: enterprise engineering and integration. Computer and Industry, 40(2-3), 83-97, doi: 10.1016/S0166-3615(99)00016-0. 
8. Lim, S.H., Juster, N., de Pennington, A. (1997). Enterprise modelling and integration. A taxonomy of seven key aspects. Computers and Industry, 34(3), 339-359, doi: 10.1016/S0166-3615(97)00069-9.

9. Luftman, J. (2003). Assessing IT-Business Alignment. Brown C.V., Topi H. (eds.) IS management handbook, 7-20. London: Auerbach Publications, doi: 10.1201/ 97814200313-93.ch1.

10. Mejabi, O.O., Singh, N. (1997). A framework for enterprise-wide integration. Computer Integrated Manufacturing, 10(1-4), 212-220, doi: 10.1080/095119297131318.

11. Milewska, E. (2016). Wdrożenie hybrydowej metody sterowania produkcją dyskretną. In: R. Knosala (ed.), Innowacje w zarządzaniu i inżynierii produkcji (pp. 759-767). Opole: Oficyna Polskiego Towarzystwa Zarządzania Produkcją.

12. Milewska, E. (2017). IT systems supporting the management of production capacity introduction. Management Systems in Production Engineering, 1(25), 60-67, doi: 10.1515/ mspe-2017-0009.

13. Nugent, E.J., Hamblin, D.J. (1996). Improved methodologies for vertical integration research. Integrated Manufacturing Systems, 7(1), 16-28, doi: 10.1108/ 09576069610108462.

14. Petrie, C.J. (1992). Enterprise integration modelling. Proceedings of the First International Conference on Enterprise Integration, Cambridge: MA.

15. Reich, B.H., Benbasat, I. (2000). Factors that influence the social dimension of alignment between business and information technology objective. MIS Quarterly, 24(1), 81-113, doi: $10.2307 / 3250980$.

16. Salmans, B. (2010). EA maturity models. In: L. Kappelman (Ed.), The SIM Guide to Enterprise Architecture. Boca Raton: CRC Press, 89-96.

17. Truman, G.E. (1998). A discrepancy-based measurement approach for data integration. Journal of Organization Computing and Electronic Commerce, 8(3), 169-193, doi: 10.1207/s15327744joce0803_1.

18. Vernadat, F.D. (1996). Enterprise modelling and integration. London: Chapman and Hall. 